\title{
Modelagem da Informação da Construção (BIM) no Ensino de Arquitetura
}

\author{
Building Information Modeling (BIM) on Architecture Teaching
}

\author{
Érica de Sousa Checcucci \\ UNIVASF / DMMDC, UFBA, Brasil \\ erica.checcucci@univasf.edu.br
}

\author{
Arivaldo Leão de Amorim \\ FAUFBA / LCAD, Brasil \\ alamorim@ufba.br
}

\author{
Ana Paula Carvalho Pereira \\ FAUFBA / LCAD, Brasil \\ apereira3@uol.com.br
}

\begin{abstract}
This paper discusses the experience of the initial phase of introduction of the BIM paradigm in the undergraduate program in Architecture and Urbanism (evening course) of FAUFBA, created under REUNI. We started from the premise that BIM should be adopted gradually and integrated with the various subjects of the course, and should be initiated through the disciplines of graphic representation. The proposal for this course is presented and practices are discussed, as they were experienced in the discipline of Computing and Design II, which deals with this paradigm. It was observed that BIM process requires significant changes, as it encountered some initial resistance from the students. However, this approach increases the understanding of building and facilitates the project documentation. Furthermore, the understanding of the scope of the paradigm was crucial to the effective use of the adopted tool.
\end{abstract}

Keywords: Architectural education; BIM; TIC; Design teaching.

\section{Introdução}

Experiências sobre o ensino do paradigma BIM (Building Information Modeling) no Brasil mostram a sua paulatina introdução nos cursos de graduação em arquitetura e em engenharia (Vincent, 2006; Andrade, 2007; Florio, 2007; Ruschel \& Guimarães Filho, 2008; Ruschel et al., 2011; Menezes et al., 2012; Romcy, Cardoso \& Miranda, 2013).

É possível perceber uma evolução nas discussões sobre o tema na academia, que inicialmente focavam vantagens e desvantagens da modelagem geométrica (3D), passando a discutir aspectos como colaboração e multidisciplinaridade nas fases iniciais da projetação. No entanto, observou-se que essa inserção no ensino encontra-se em fase inicial, e se dá geralmente de forma pontual, em uma ou duas disciplinas do currículo - representação gráfica, e ou projeto de arquitetura. Poucas experiências relatam integração com disciplinas técnicas (instalações, estrutura, construção, etc.) especialmente junto à graduação. Isto evidencia uma adoção incipiente do paradigma, revelando a necessidade de estratégias mais efetivas para acelerar a difusão, adoção e amadurecimento do ensino de BIM no país.

Este trabalho relata a experiência de introdução do paradigma BIM no curso de graduação em Arquitetura e Urbanismo (noturno) da Faculdade de Arquitetura da Universidade Federal da Bahia (FAUFBA), criado em 2008 no âmbito do Plano de Reestruturação e Expansão das Universidades Federais (REUNI).
Alguns dos principais aspectos intrínsecos do paradigma BIM que dificultam a sua adoção seja no ensino, seja na prática profissional, são a complexidade envolvida, a vastidão do escopo a que se propõe, a sofisticada plataforma tecnológica e os significativos custos envolvidos.

O BIM contempla um conceito complexo, pois compreende um processo colaborativo e integrado que utiliza um ambiente gráfico computacional tridimensional e paramétrico para execução dos projetos, e outras atividades que abrangem o ciclo de vida da edificação, desde o estudo de viabilidade, a projetação, o planejamento da construção, a construção, a operação, a manutenção, até a demolição ou a requalificação. $O$ uso do BIM favorece a integração entre essas fases, contribuindo para o gerenciamento das atividades, possibilitando a redução de custos, de conflitos entre disciplinas e favorecendo a comunicação entre os diversos agentes envolvidos com a edificação durante o seu ciclo de vida.

Outro aspecto dificultador está relacionado a plataforma tecnológica, pois para que o BIM seja utilizado em todo o ciclo de vida da edificação, o edifício virtual deverá ser modelado através de diferentes ferramentas, com diferentes objetivos. A troca de informações entre esses programas deve ocorrer sem a degradação dos dados, evitando o retrabalho de inserção de elementos perdidos, e garantindo a utilização eficiente da informação. Por isso, a definição da plataforma de trabalho, da 
rede e pacotes de software, compõe um aspecto essencial da adoção.

Por último, a implantação também é dificultada pelo significativo custo da infraestrutura necessária, que compreende: mão de obra qualificada e proficiente, implicando em treinamento; hardware adequado às ferramentas, solicitando, em geral, máquinas com grande capacidade de processamento; e ferramentas específicas para cada uso. Devido ao ritmo das inovações, estas tecnologias possuem rápida obsolescência e preços elevados, resultando em necessidade de atualizações frequentes e representando custos significativos.

Além das dificuldades próprias do paradigma, tem-se o ensino de graduação, seja de Arquitetura ou de Engenharia Civil, calcado em disciplinas isoladas onde em cada uma delas são tratados de temas específicos e especializados, mas de forma fragmentada, esquecendo-se muitas vezes de que a edificação constitui uma unidade única, destinada a cumprir um determinado papel, ou mais de um, ao longo da sua vida útil.

Em função disto, é preciso entender que este tipo de abordagem não mais é capaz de dar conta dos desafios ambientais, tecnológicos e socioeconômicos que estão colocados na contemporaneidade.

Assim, o desafio da introdução do paradigma BIM no ensino passa inicialmente pelo entendimento da importância de se enfrentar o ciclo de vida da edificação como um todo e contínuo, e não o enfrentamento de forma parcial e assíncrono que normalmente acontece: incialmente, a projetação nos cursos de Arquitetura, seguida pela construção nos cursos de Engenharia Civil.

Assumindo-se esse entendimento, no segundo momento torna-se evidente a necessidade da integração das várias disciplinas, o que se constitui talvez no maior desafio, não só em função da especialização das mesmas, mas, sobretudo, pelos profissionais nelas envolvidos. Alterar rotinas de trabalho consolidadas, práticas consagradas e culturas estabelecidas, talvez seja o maior desafio a ser superado no processo de adoção do paradigma. Isto só será possível na medida em que os vários profissionais entendam a importância da integração e estejam dispostos a desenvolver novas práticas colaborativas.

O terceiro aspecto a ser considerado é como inserir o paradigma neste complexo contexto, que envolve duas formações complementares e cada vez mais separadas, um grande número de disciplinas e profissionais, que vai demandar profundas alterações em conceitos, conteúdos e metodologias. O paradigma BIM ou simplesmente BIM, ou ainda, a Modelagem da Informação da Construção, não pode ser entendida como uma nova ou mais uma disciplina. Isto seria impraticável, dada a sua complexidade.

Por outro lado, BIM deve ser visto como uma nova forma de abordagem da edificação e do seu ciclo de vida. Assim, os novos conteúdos, sejam conceitos, tecnologias e métodos, precisam ser cuidadosamente integrados nas disciplinas já existentes nos referidos cursos, e estas adequadamente relacionadas entre si.

\section{O Contexto da Adoção}

A introdução do BIM no curso noturno da FAUFBA partiu de premissas pedagógicas distintas das até então empregadas no curso de graduação já existente (diurno) nessa Faculdade. Assim, uma das premissas assumidas foi a decisão de se trabalhar BIM integrado às diversas disciplinas do curso, sempre que isto se justificasse, e representasse ganhos de competência para os futuros profissionais. No entanto, esta adoção não se daria de forma repentina, mas sim de forma sutil e incremental, de modo a evitar que possíveis equívocos desta estratégia pudessem resultar em insucesso e viessem a comprometer esta adoção. A escolha de um caminho errado ou uma estratégia inadequada poderia ser fatal para a implantação.

No presente experimento, favorecendo a esta abordagem, estava o fato de ser este um curso novo, onde a cada ano seriam implantadas as novas disciplinas até que toda a grade curricular estivesse em pleno funcionamento.

Nesse sentido, a estratégia utilizada se alinha com o pensamento de autores, como Rebolj, Menzel e Dinevski (2008); Sacks e Barak (2010) e Wong, Wong e Nadeem (2011), que defendem a adoção de BIM integrada às diversas disciplinas da grade curricular, em contraponto a implantação pontual do paradigma.

Rebolj, Menzel e Dinevski (2008) observam que, de um modo geral, os cursos são fragmentados, fornecem conhecimentos limitados sobre aspectos específicos da Ciência da Computação e da Tecnologia da Informação (TI) e que esta forma segmentada e desconectada de absorver essa dimensão não é capaz de educar corretamente os profissionais para a área da construção civil, onde o potencial da $\mathrm{TI}$ precisa ser largamente utilizado de forma integrada.

Similarmente, Wong, Wong e Nadeem (2011) defendem que a adoção integrada se alinha mais com demandas da indústria da construção, que busca profissionais capazes de aplicar seus conhecimentos em situações práticas, as quais podem ser simuladas utilizando BIM.

Sacks e Barak (2010), afirmam que o trabalho com BIM deve ser iniciado ainda nos primeiros estágios da graduação e continuado ao longo da formação do estudante. Os autores falam que um princípio assumido no curso da Technion University, em Israel, do qual fazem parte, é que o desenvolvimento de uma sólida base conceitual sobre BIM e o trabalho prático com uma ferramenta de modelagem geométrica permitirá aos alunos, posteriormente, utilizarem outras ferramentas nas diversas disciplinas e na vida profissional com uma reduzida curva de aprendizagem.

Como vantagem da estratégia de adoção integrada do BIM aos processos de ensino-aprendizagem, pode ser citada que provavelmente demandará uma menor alteração na estrutura da matriz curricular de cursos já vigentes, possivelmente facilitando a introdução do tema na formação do aluno, já que o tempo necessário seria distribuído entre diferentes disciplinas e; os alunos teriam possibilidade de trabalhar as diversas especialidades com diferentes professores, tendo acesso a diferentes formas de utilização da modelagem da informação da construção nas várias fases do ciclo de vida da edificação.

Além disto, a abordagem integrada do paradigma BIM e a automação de processos, faz com que conteúdos possam ser suprimidos e outros otimizados, de forma que tal introdução não 
signifique um aumento na carga horária da disciplina ou no curso como um todo.

Como contraponto, as maiores dificuldades desta abordagem são: a necessidade de ter um maior número de docentes com formação em BIM, que assimilem o seu conceito mais amplo; a necessidade do estabelecimento de um efetivo trabalho colaborativo entre eles, de forma a evitar a aprendizagem fragmentada e pouco significativa, e, eventualmente, a possibilidade de ser necessário criar novos componentes curriculares para trabalhar conteúdos que não possam ser abordados na matriz curricular já existente, com a profundidade e a abrangência desejada.

Defende-se que esta estratégia integrada possibilitará uma formação mais abrangente e eficaz para o estudante, que irá trabalhar a Modelagem da Informação da Construção em diferentes momentos da sua formação, em um processo continuado que inicia no seu acesso ao curso e que fecha o primeiro ciclo com a sua formatura.

Nesse contexto, a abordagem proposta foi possível na FAUFBA tendo em vista um novo curso de graduação, cuja implantação total estava prevista para cinco anos, e cuja grade curricular e conteúdos já foram pensados com alto grau de integração. Embora este fosse um aspecto essencial, contudo, não foi o principal aspecto que viabilizaria a proposta, como explicitado a seguir.

O novo curso demandou a contratação de novos professores. Assim, foram estabelecidos perfis e competências para esses novos professores, calcados na multidisciplinaridade, na integração e na colaboração, de modo a que fossem capazes de enfrentar os desafios estabelecidos na proposta pedagógica. Deste modo, para que tudo pudesse acontecer da forma concebida, foram preparados os editais para os concursos públicos, montadas as bancas examinadoras e implantadas as novas disciplinas do novo curso.

Era evidente, que nenhum desses novos professores seriam experts em BIM, até porque os poucos existentes no país não estariam disponíveis. Por esta razão, eles teriam que ser formados num segundo momento. Entretanto, ter-se-ia um curso estruturado para ser ministrado num contexto BIM, por uma equipe de novos e competentes professores aptos a enfrentarem o desafio estabelecido. Assim, a opção pelo uso das tecnologias seria apenas uma questão de tempo.

Outra decisão importante para assegurar a integração e a colaboração entre os professores, foi a decisão de adotar uma única turma de todas as disciplinas com um módulo de 45 alunos. As disciplinas teóricas e específicas são ministradas pelo professor especialista na área, e as disciplinas de projeto de arquitetura, ministradas por três diferentes professores com especializações diversas, estabelecendo-se assim efetivamente as bases para a integração e a colaboração.

Deste modo, seguindo a estratégia traçada, a adoção iniciou-se por onde deveria, e onde, felizmente, já havia uma maior competência estabelecida, advinda da longa experiência no ensino de Computer Aided Design (CAD) através do Laboratório de
Computação Gráfica Aplicada à Arquitetura e ao Desenho (LCAD) da FAUFBA.

\section{Os Primeiros Desafios}

Descreve-se nesta seção a fase inicial da implantação de BIM no Curso Noturno, e especificamente nas disciplinas associadas ao ensino de Desenho e de Representação Gráfica. Seus conteúdos relacionam-se com o desenho geométrico, o desenho projetivo, a perspectiva, a geometria descritiva, o desenho técnico básico e desenho arquitetônico, e o desenho de observação, foram organizados de modo a constituir um conjunto de quatro componentes curriculares, ministrados cada um deles em diferentes semestre, com 68 horas de carga horária cada.

A seguir descreve-se resumidamente as principais características desses componentes, como objetivos, conteúdos e metodologia, onde são trabalhados aspectos conceituais e práticos da representação gráfica e da representação arquitetônica, sempre de forma sistêmica, agregando crescente complexidade à abordagem seja nos objetos representados, seja no uso das Tecnologias de Informação e Comunicação (TIC).

\section{Arq A16 - Desenho de Observação}

Este componente é ministrado sempre no primeiro semestre do curso, e visa desenvolver no aluno a sua capacidade de expressão gráfica, através de técnicas de representação gráfica à mão livre, utilizando, lápis, canetas diversas, pincéis etc. Este é o único dos componentes desse grupo onde não são empregados recursos computacionais por parte dos alunos para o desenvolvimento dos seus trabalhos por entender-se que esta habilidade de criar e representar à mão livre empregando diversas técnicas é essencial na formação do arquiteto, e que se constitui numa forma rápida e flexível para o registro do pensamento projetual e o refinamento das ideias. Sendo que esta habilidade deve ser incentivada e aperfeiçoada ao longo do curso, especialmente durante o ensino de projeto através do esboço cotado.

\section{Arq A20 - Desenho Projetivo}

Este componente do grupo é sempre ministrado no segundo semestre do curso, e contempla parte dos conteúdos de Geometria Descritiva, como a terminologia, as projeções de pontos, retas e planos, posições relativas destes; e os conceitos da perspectiva linear e do desenho projetivo, visando devolver a visão e o raciocínio espacial do aluno. Contempla ainda no conteúdo a introdução ao desenho técnico e ao desenho arquitetônico. Aqui rompe-se com os clássicos cursos de representação gráfica, visto que não são utilizados os recursos tradicionais de desenho e sim ferramentas computacionais. Assim, todas as explanações, exercícios e trabalhos são desenvolvidos através da ferramenta SketchUp, numa abordagem 2D e 3D. Aqui é importante registrar que parte dos novos professores contratados para o curso ofereceu certa resistência em assumir esta orientação, preferindo voltar aos instrumentos tradicionais, o que não foi aceito nessa disciplina.

\section{Arq A25 - Informática e Desenho I}

Este componente é sempre ministrado no terceiro semestre do curso, e nele são introduzidos os primeiros conceitos sobre BIM e desenvolvidos os conteúdos sobre CAD, tipos de ferramentas, recursos, e aplicações, sempre a partir de um viés integrado à 
Modelagem da Informação da Construção. Ainda como conteúdo está a representação arquitetônica apurada através do uso de editores de desenhos, e a produção das pranchas de desenho para documentação do projeto e execução da obra, sendo empregada a ferramenta AutoCAD, da Autodesk.

\section{Arq A37 - Informática e Desenho II}

Finalmente, este quarto componente é sempre ministrado no sexto semestre do curso, e ocupa-se especificamente na aplicação de BIM na execução de projetos de arquitetura. São introduzidos os conceitos fundamentais do paradigma como colaboração, integração, interoperabilidade, modelagem paramétrica, CADnD, ciclo de vida da edificação, criação de templates, componentes arquitetônicos e as bibliotecas ou famílias destes; ferramentas CAD-BIM; construção, manipulação e extração de informações do modelo. Como ferramenta para o desenvolvimento da parte instrumental foi adotado o Revit Architecture, da Autodesk, através do qual são desenvolvidos os modelos BIM na projetação arquitetônica, e em seguida, a representação das pranchas para documentação do projeto.

Através deste conjunto de disciplinas dá-se a primeira fase do ciclo de implantação de BIM no curso, onde são solidamente assentadas as bases do paradigma. As demais aplicações deverão ser expandidas nas disciplinas de projetos de arquitetura, de estruturas, de instalações prediais, e de construção e planejamento das obras, dentre outras.

Nesse contexto, fica excluída apenas a fase de operação e manutenção das edificações, visto que não foram criadas as disciplinas para contemplar estas especialidades, por não fazerem tradicionalmente parte da estrutura do curso de graduação de Arquitetura. Entretanto, com a implantação e a consolidação das demais fases do ciclo de vida, espera-se que seja possível a criação de disciplinas optativas capazes de suprir esta lacuna.

\section{As Experiências em Arq A37}

Discute-se nesta seção as experiências vivenciadas durante os semestres de 2011.2 e 2012.2, na condução do componente curricular Arq A37 - Informática e Desenho II, que trata especificamente do paradigma BIM como um todo, tendo ênfase no desenvolvimento do projeto arquitetônico, conforme aqui descrito. Os procedimentos pedagógicos se deram através de aulas expositivas teórico/práticas abordando o conteúdo programático e aulas práticas com exercícios para fixação dos conhecimentos usando o programa Revit Architecture, além de acompanhamento e orientação em sala de aula para o desenvolvimento dos exercícios e dos trabalhos práticos.

As avaliações foram realizadas através da aplicação de uma prova teórica, que abordou os conceitos fundamentais do paradigma e de um conjunto de exercícios realizados durante o semestre (exercícios de modelagem, leitura e fichamento de textos sobre $\mathrm{BIM}$ e fichamento de ferramentas BIM). Estes exercícios tiveram o objetivo de consolidar o aprendizado através de pesquisa dos principais conceitos e aplicações do paradigma nas diversas fases do ciclo de vida da edificação. No exercício de fichamento de software, o aluno deveria informar o nome do programa, versão, fabricante, as áreas em que o mesmo poderia ser utilizado/fase do ciclo de vida da edificação, aplicação principal, principais características e funcionalidades, entre outros aspectos.
Nos exercícios de modelagem, foi representada a forma arquitetônica e a estrutura de uma edificação, diferente em cada semestre. Estas modelagens foram sendo realizadas à medida que os subsídios para tal eram discutidos em sala de aula e o exercício foi o mesmo para todos os alunos. Este primeiro modelo serviu de base para que os alunos testassem os principais comandos do programa e se familiarizassem com a lógica do paradigma BIM.

A terceira e última avaliação/exercício foi o desenvolvimento de um trabalho individual e prático, orientado, onde foi realizada a modelagem básica de uma edificação escolhida pelo aluno. Para iniciar o trabalho, foi solicitado o preenchimento de uma ficha de acompanhamento do projeto, composta por identificação; descrição das características do projeto e tabela com todos os componentes que seriam modelados e suas especificações por categorias. Neste momento, os alunos já tinham consciência da necessidade de realizar um planejamento prévio à modelagem.

Após o planejamento foram desenvolvidos os componentes básicos iniciais que seriam utilizados, como as paredes, esquadrias, etc. Estes componentes, em geral, foram derivações da biblioteca já existente no programa. No entanto, alguns alunos que tinham conhecimento sobre modelagem de famílias, criaram objetos específicos para seus trabalhos. Este exercício de customização de componentes contribuiu para o aprendizado sobre materiais construtivos, composição dos objetos da edificação e dos parâmetros envolvidos na sua criação.

Também foi trabalhada a criação de um arquivo padrão (template) no qual foram definidas a nomenclatura para famílias de objetos, vistas pré-definidas, customização de textos e cotas, além de organização de arquivos e diretórios. Assim, cada aluno criou o seu próprio arquivo, com os elementos necessários e específicos para o desenvolvimento do modelo, com os materiais, unidades de medida, níveis, elevações, eixos, formatos de folhas de desenhos, etc.

A edificação sugerida para o trabalho final deveria possuir grau médio de complexidade, considerando a sua forma, tamanho, existência de diferentes pavimentos, desníveis, escadas, rampas e variedade nos tipos de esquadrias e materiais. Após a confecção do modelo no Revit, os alunos deveriam gerar as pranchas para a documentação de forma a permitir a construção da edificação, conforme as normas da ABNT para a representação arquitetônica.

A modelagem de edificações diferentes por parte dos alunos permitiu que fossem analisados e resolvidos variados problemas referentes à criação do modelo BIM. Os alunos que tinham mais experiência ou que conseguiam se dedicar mais, puderam se arriscar em criar formas mais complexas, testar comandos de modelagem mais avançados e opções de representação mais refinadas. Aqueles que tinham mais dificuldades criaram modelos mais simples, porém vivenciado as experiências dos colegas, puderam vislumbrar as potencialidades do programa. Como mínimo, foi exigido que a edificação (qualquer que tenha sido a sua complexidade) fosse completamente representada, segundo as normas da ABNT.

A maioria dos alunos preferiu utilizar uma edificação que já havia elaborado anteriormente empregando o AutoCAD, ao invés de modelar a que estava sendo desenvolvida na disciplina de ateliê 
de projeto. A escolha de uma edificação já conhecida facilitou a confecção do modelo BIM utilizando o Revit.

Em ambos semestres letivos foi observada resistência dos estudantes em alterar o seu processo de trabalho, incorporado ao longo da sua formação nos semestres anteriores, pois o BIM traz em si mudanças na forma de conduzir a projetação, tendo que ser concebidos e definidos detalhes em fases ainda iniciais do processo, como por exemplo, as definições das paredes - que espessura, materiais e revestimentos elas possuem - para só depois de definidos e criados estes componentes, passarem a modelar as paredes da edificação. Vale ressaltar que esta disciplina está no sexto semestre da grade curricular do curso de arquitetura noturno. Contudo, observou-se que essa resistência diminuiu na medida em que o curso foi avançando, com a crescente compreensão do novo paradigma e o domínio adquirido sobre a ferramenta. Tudo isto contribuiu para o desenvolvimento de trabalhos de qualidade, apresentados ao final do semestre.

Assim, confirmou-se que o paradigma BIM exige mudanças, tanto no que se refere às práticas de projeto quanto às de ensino, e estas foram enfrentadas com determinação pela equipe de professores. Inicialmente houve um pouco de resistência por parte dos alunos, entretanto aqueles alunos que ofereceram maior rejeição ao processo foram os que ao final do curso, demonstraram maior interesse na nova tecnologia. Expressaram ainda o desejo de continuar estudando BIM para aplicá-lo ao longo do curso e da carreira. Ficou evidente que isto só foi possível a partir do pleno entendimento do paradigma, de seus benefícios e de certo nível de domínio do aluno sobre a ferramenta.

\section{Considerações Finais}

Este breve texto sumariza a introdução do paradigma BIM no curso de graduação em Arquitetura e Urbanismo (noturno) da FAUFBA. As duas experiências realizadas produziram resultados satisfatórios, demonstrando claramente que a estratégia de adoção proposta foi acertada. Fica evidente que ainda existem muitos aspectos desta e das demais disciplinas que precisam ser ajustados entre si, e eventualmente complementados, de modo a otimizar a carga horária dos componentes e suprir o aluno dos conhecimentos mínimos necessário à uma prática profissional condizente com as necessidades do mercado de trabalho.

Por outro lado, para que isto venha acontecer, é necessário que os conhecimentos adquiridos nesse grupo de disciplinas sejam efetivamente utilizados nas demais disciplinas, especialmente naquelas que envolvem a concepção e o desenvolvimento de projetos. Entretanto, na medida em que os alunos compreendam a importância e a potencialidade do paradigma BIM, e estejam aptos a utilizá-lo nos seus trabalhos, esta deverá ser a escolha natural para o desenvolvimento dos seus exercícios acadêmicos, considerando-se todas as vantagens propiciadas pela tecnologia.

$\mathrm{Na}$ sequencia, evidencia-se a necessidade de prosseguir com a adoção plena do paradigma com a sua implantação nas disciplinas de instalações, estruturas e construção. Assim, a tarefa que si impõe no momento é a formação em BIM dos demais professores que ministram estas disciplinas, de modo a que paulatinamente possam ir introduzindo o paradigma nesses conteúdos, até atingir o pleno uso das tecnologias nos referidos componentes curriculares. Concluindo, tem-se a consciência de que o Curso Noturno da FAUFBA ainda não atingiu o objetivo almejado de utilizar BIM em todas as disciplinas nas quais o paradigma pode ser adotado. No entanto, o caminho já está traçado e é inabalável a decisão de se seguir este rumo.

\section{Agradecimentos}

Os autores registram seus agradecimentos à UNIVASF e a FAPESB, pelo apoio ao projeto de doutorado em curso; ao CNPq pela bolsa de produtividade em pesquisa concedida; à CAPES, pelo apoio ao projeto da Rede BIM-Brasil e à FINEP, pelo apoio do projeto/rede Tecnologias da Informação e Comunicação aplicadas à construção de Habitações de Interesse Social.

\section{Referências}

Andrade, M. L. V. X. (2007). Computação gráfica tridimensional e ensino de arquitetura: uma experiência pedagógica. In: Graphica 2007 Congresso Internacional de Engenharia Gráfica nas Artes e no Desenho, 7., 2007, Curitiba. Anais... Curitiba: UFPR, 2007. 1 CD.

Florio, W. (2007). Contribuições do Building Information Modeling no processo de projeto em arquitetura. In: Tic 2007 - Encontro de Tecnologia da Informação e comunicação na construção civil, 3., 2007, Porto Alegre. Anais... Porto Alegre: ANTAC, 2007.

Menezes, A. M.; Viana, M. L. S.; Pereira Júnior, M. L.; Palhares, S. R. (2012). Impacto da tecnologia BIM no ensino de projetos de edificações. In: Congresso Brasileiro de Educação em Engenharia, 40., 2012, Belém. Anais... Belém: ABENGE, 2012.

Rebolj, D., Menzel, K. \& Dinevski, D. (2008). A Virtual Classroom for information Technology in Construction. Computer Applications in Engineering Education. V. 16, Issue 2, p. 105-114, 2008. Disponível em: <http://onlinelibrary.wiley.com/doi/10.1002/ cae.20129/pdf>. Acesso em: 18 fev. 2013.

Romcy, N. M. S.; Cardoso, D. R.; Miranda, N. M. (2013). BIM e Ensino: Experiência acadêmica realizada na Universidade Federal do Ceará. In: Simpósio Brasileiro de Qualidade do Projeto no Ambiente Construído, 3.; Encontro de Tecnologia de Informação e Comunicação na Construção, 6., 2013, Campinas, Brasil. Anais... Porto Alegre: ANTAC, 2013

Ruschel, R. C. \& Guimarães Filho, A. B. (2008). Iniciando em CAD 4D. In: Workshop Brasileiro Gestão do Processo de Projeto na Construção de Edifícios, 8., 2008, São Paulo. Anais... São Paulo: USP, 2008.

Ruschel, R. C.; Andrade, M. L. V. X.; Sales, A. A.; Morais, M. (2011). O ensino de BIM: exemplos de implantação em cursos de engenharia e arquitetura. In: Tic 2011 - Encontro de Tecnologia de Informação e Comunicação na Construção, 5., 2011, Salvador. Anais... Salvador: UFBA, 2011.

Sacks, R.; Barak, R. (2010). Teaching Building Information Modeling as an Integral Part of Freshman Year Civil Engineering Education. Journal of professional issues in engineering education and practice. ASCE, v. 136, n. 1, p. 30-38, Jan. 2010. Disponível em: <http://www.ascelibrary.org>. Acesso em: 10 mar. 2013.

Vincent, C. C. Ensino de projeto: digital ou manual? (2006). In: Congresso da Sociedade Iberoamericana de Gráfica Digital, 10., 2006, Santiago do Chile. Anais... Santiago do Chile: Universidad de Chile, 2006. 1 CD.

Wong, K. A.; Wong, K. F.; Nadeem, A. (2011). Building Information Modeling for tertiary construction education in Hong Kong. Journal of Information Technology in Construction (ITCon). v. 16, p. 467-476, 2011. Disponível em: <http://www.itcon.org/ 2011/27>. Acesso em: 14 fev. 2013. 